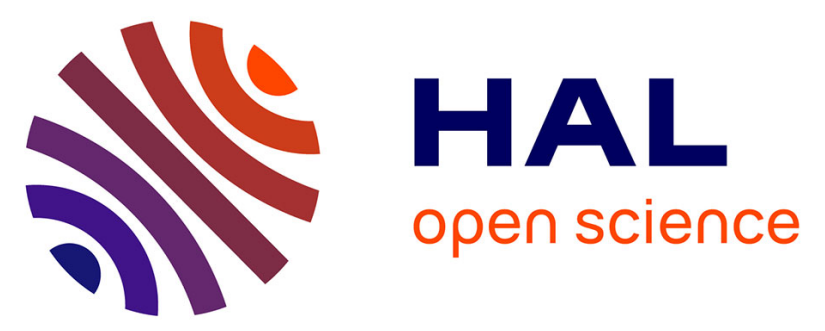

\title{
Comment on "Kinetics and thermodynamics of Eu(III) adsorption onto synthetic monoclinic pyrrhotite" by Y. Zhu et al., Journal of Molecular Liquids, 218 (2016), 565-570
}

Nicolas Finck, Johannes Luetzenkirchen, Khalil Hanna, Thomas Rabung

\section{To cite this version:}

Nicolas Finck, Johannes Luetzenkirchen, Khalil Hanna, Thomas Rabung. Comment on "Kinetics and thermodynamics of $\mathrm{Eu}(\mathrm{III})$ adsorption onto synthetic monoclinic pyrrhotite" by Y. Zhu et al., Journal of Molecular Liquids, 218 (2016), 565-570. Journal of Molecular Liquids, 2016, 224 (Part A), pp.1022-1024. 10.1016/j.molliq.2016.10.094 . hal-01475472

HAL Id: hal-01475472

https://hal-univ-rennes1.archives-ouvertes.fr/hal-01475472

Submitted on 23 Feb 2017

HAL is a multi-disciplinary open access archive for the deposit and dissemination of scientific research documents, whether they are published or not. The documents may come from teaching and research institutions in France or abroad, or from public or private research centers.
L'archive ouverte pluridisciplinaire HAL, est destinée au dépôt et à la diffusion de documents scientifiques de niveau recherche, publiés ou non, émanant des établissements d'enseignement et de recherche français ou étrangers, des laboratoires publics ou privés. 


\title{
Comment on "Kinetics and thermodynamics of $\mathrm{Eu}$ (III) adsorption onto synthetic
} monoclinic pyrrhotite" by Y. Zhu et al., Journal of Molecular Liquids, 218 (2016), 565 570.

\author{
Nicolas Finck $^{1 *}$, Johannes Lützenkirchen ${ }^{1}$, Khalil Hanna ${ }^{2}$, Thomas Rabung ${ }^{1}$
}

${ }^{1}$ Institute for Nuclear Waste Disposal (INE), Karlsruhe Institute of Technology (KIT), P.O. Box 3640, 76021 Karlsruhe, Germany.

${ }^{2}$ Ecole Nationale Supérieure de Chimie de Rennes, CNRS,UMR 6226, 11, Allée de Beaulieu CS 50837, 35708Rennes Cedex 7, France

*corresponding author: Phone: +49 (0) 721-6082-4321, Fax: +49 (0) 721-6082-3927, e-mail: nicolas.finck@kit.edu.

\begin{abstract}
The paper of Zhu et al. [1] is of great interest, since it reported adsorption data of $\mathrm{Eu}(\mathrm{III})$ onto pyrrhotite, an uninvestigated solid surface to date. We are of the opinion that the system is of relevance in the context of nuclear waste disposal in deep repositories. In the study, Eu(III) is used as an analogue for trivalent actinides and pyrrhotite might be a relevant mineral under reducing conditions. Unfortunately, for readers interested in using the uptake data for developing a surface complexation model, some crucial information concerning experimental conditions is missing and some statements in the text require some clarification. We aim here to raise some relevant questions in a constructive way, to achieve a correct understanding of this interesting data.
\end{abstract}

\section{Keywords}

Europium; pyrrhotite; adsorption; complexation; thermodynamics 


\section{Highlights}

In a recent paper in this journal, information concerning experimental conditions is missing.

The present comment intends to improve the paper by suggesting clarifications and modifications.

A surface complexation model may be developed using the complete uptake data.

\section{Introduction}

Europium is a member of the lanthanide series, and often used as non-radioactive chemical homologue of trivalent actinides [2] because of its very similar size and its oxidation state. The authors [1] used pyrrhotite as adsorbent for the uptake study. The solid compound was prepared by calcination of pyrite. Air-exposed pyrrhotite or pyrrhotite in aqueous suspension can be easily oxidized and the outer most surfaces of the solid particles are then mainly composed of ferric oxyhydroxides [3]. Surface oxidation would thus generate surface properties similar to those of iron(III) (oxy)(hydr)oxides [4]. In turn, this would change the adsorption properties from that of pristine pyrrhotite and it can be assumed that $\mathrm{Eu}(\mathrm{III})$ is then taken up at surface sites of those iron(III) minerals, which are known to be quite reactive.

\section{Discussion}

\subsection{Sample preparation and characterization}

When working with systems containing reduced species such as iron sulfide or with sorbate (e.g., $\mathrm{Eu}(\mathrm{III}))$ highly reactive toward complexation by ligands such as carbonates, the control of the chemical conditions represents an essential aspect. Working under $\mathrm{N}_{2}$ or Ar atmosphere is mandatory and further purification by bubbling through e.g., washing bottles containing hydroxide solution and reducing agents would be highly beneficial to remove traces of oxygen or carbon dioxide and thereby prevent surface oxidation and europium complexation by carbonate. Unfortunately such detailed information is not provided in the work of Zhu et al. [1]). This information would help understanding some experimental results such as surprising XPS spectra where the intensity of the O $1 s$ line is about two times higher than that of the $S 2 p$ at the surface of pyrrhotite hinting at surface oxidation.

Additional detail on sample preparation would be appreciated to understand the various steps. For example, the pre-treatment was intended for removal of impurities present in or at the 
surface of the starting material. Zhu et al. [1] may have collected X-ray diffraction (XRD) and infrared (IR) data on the starting material to identify impurities, and adapt the pre-treatment accordingly. However, this is not mentioned. The authors followed the procedure of Bhargava et al. [5] to prepare pyrrhotite, but this latter group selected starting pyrite samples with minimum levels of impurities and did not (have to) chemically pre-treat their samples, and used ethanol to avoid sample oxidation.

After pyrrhotite preparation, the solid phase was indeed characterized by techniques such as XRD and IR spectroscopy by Zhu et al. [1]. Based on XRD data reported by Tokonami et al. [6], the most significant and intense peaks on the X-ray diffractogram are expected in the 10$30^{\circ} 2$ theta range, but we could not retrieve those peaks in that angular range in the data of Zhu et al. [1]. In the case of preferential crystallite orientation, peaks of (very) low intensity should still be visible, but no peak is present in that range on the diffractogram. Nevertheless, we would contend that the indexed diffractogram corroborates the presence of pyrrhotite. There are also additional small peaks which are non-indexed $\left(\sim 26^{\circ}\right.$ and $\left.\sim 65^{\circ}\right)$ and could correspond to impurities. The identification of additional phases is important in uptake studies because such phases could also bind cations like europium. On the IR spectrum, some band assignments are unexpected given the structure of pyrrhotite. We agree that the bands at 3420 and $1622 \mathrm{~cm}^{-1}$ can be attributed to adsorbed water (OH stretching and deformation). For the other bands, the assignment might call for some questions. For example, the band near 800 $\mathrm{cm}^{-1}$ may also be attributed to silica / quartz, and this could originate from impurities present in the starting natural material (see below). On the X-ray diffractogram of pyrrhotite, there are also diffraction peaks not belonging to the compound of interest. For example, the peak at $\sim 26^{\circ}$ could indicate the presence of quartz, and this would be consistent with IR data. Similarly, the band at $1088 \mathrm{~cm}^{-1}$ on the IR spectrum could be attributed to cristobalite [7], a high temperature polymorph of silicon dioxide, which was not detected by XRD though. Alternatively, this band of high intensity could originate from an X-ray amorphous phase. Indeed, the authors assign this band to $\mathrm{Si}-\mathrm{O}-\mathrm{Si}$ groups from the tetrahedral sheet, which is surprising because pyrrhotite is not supposed to contain Si. Possible presence of silica could explain the relatively high adsorption of $\mathrm{Eu}(\mathrm{III})$ at low $\mathrm{pH}$ (i.e. $30 \%$ uptake). The presence of $\mathrm{Si}-\mathrm{O}-\mathrm{Si}$ groups from tetrahedral sheets could perhaps result from the presence of clay-like material. This would explain uptake at low pH (the absence of salt effect on Eu uptake does not support this speculation) and could even be responsible for Eu(III) uptake at higher $\mathrm{pH}$. The steeper part of the adsorption edge (starting around $\mathrm{pH}$ 5) coincides well with adsorption 
patterns of europium on other sulfide minerals, e.g. on non-oxidized pyrite uptake starts at $\mathrm{pH}$ 6, while on oxidized pyrite it starts at $\mathrm{pH} 4$ [8]. Below $\mathrm{pH} 5$ a different slope on the uptake curve occurs which might point to an additional/separate mechanism. Beside the possible effect of silica (not so much in terms of a silica, but rather in terms of a clay-like surface), the instability of pyrrhotite might affect the uptake. This latter point could also explain differences between "equilibrium" and kinetic uptake data, discussed below.

The surface of the solid was characterized by potentiometric acid-base titration. However, to judge the quality of the pyrrhotite titration results, it is necessary to know how much solid surface was present in the titration vessel. Unfortunately, the unit of the 0.3 quantity (most probably $0.3 \mathrm{~g}$ ) is missing in the text. In this context the solution volume in the titration vessel would be required as well as the specific surface area of the sorbent. Details on potentiometric titrations to determine the surface charge of minerals have been published elsewhere $[9,10]$. We suspect that there may have been too little surface area in the titration vessel, since (based on Figure 1D [1]) in the $\mathrm{pH}$ range between 6 and 9, the total proton concentration changes by no more than $0.2 \mathrm{mM}$. To reach $\mathrm{pH} 11$ from a starting $\mathrm{pH} 6$ with TOTH $=0$, a total proton concentration of approximately $-0.001 \mathrm{M}$ in a blank titration is required, while the authors reported approximately $-0.0006 \mathrm{M}$ in the presence of the solid, which should require more than the blank. We wonder therefore if Figure 1D may have been misprinted.

Although Zhu et al. [1] report a point of zero charge of 6, the point of zero charge of a solid cannot be determined by potentiometric titration at one single ionic strength. It will turn out to be at zero total proton concentration in that case (Figure 1D). Titrations at various salt levels could be obtained to get the so-called common intersection point (CIP). For well-behaved oxides this CIP will be the pristine point of zero charge and coincides with the isoelectric point (IEP) obtained by an electrokinetic method. The latter is the most direct method and electrokinetic investigations of a wide range of sulfide minerals have been analyzed by Bebie et al. [11]. Those authors report that most of the IEPs are below $\mathrm{pH} 2$, which supports our concerns about the point of zero charge of 6 . Others report negative zeta-potentials for pyrrhotite above $\mathrm{pH} 2$ [12]. Oxidation of pyrite has been shown to increase the IEP of pyrite from $\mathrm{pH} 2$ to 3 only [8]. In another study it increased to higher $\mathrm{pH}$ values, depending on the time of exposure to air (to about pH 6 after 19 hours).

\subsection{Kinetic and equilibrium uptake data}


We have compared the uptake data from the kinetic study (Figure 2A) to those of the equilibrium data in Figure 3A. According to the description we assume that all data were collected at $10 \mathrm{mg} / \mathrm{L} \mathrm{Eu}$. This would mean that at $\mathrm{pH} \mathrm{3,} \mathrm{about} 4 \mathrm{mg} / \mathrm{g}$ Eu is adsorbed. With 2 $\mathrm{g} / \mathrm{L}$ this makes a total of $8 \mathrm{mg} / \mathrm{L}$ (i.e. $80 \%$ ). According to Figure $3 \mathrm{~A}$ less than $40 \%$ should be adsorbed. We also note that the $\mathrm{y}$-axis of Figure $2 \mathrm{~B}$ is unclear, since units are missing. It would be of interest to compare the uptake data from the isotherms (in Figure 4A) to those in Figure 3A. For $\mathrm{pH} 3$ and 5, using the Langmuir parameters from Table 2, we estimate for a total Eu concentration of $10 \mathrm{mg} / \mathrm{L}$ about 60 and 70 percent adsorption, compared to 40 and 50 percent on Figure 3A, respectively. Further, we believe that the data on Figures 4C and 4D are in disagreement. We also speculate about an error in processing the data on the $\mathrm{x}$-axis from linear to logarithmic. As an example $\log (40)$ would be 1.6, while on Figure 4D it is about 1.0.

\subsection{Solution and surface speciation}

In the final part, we have some concerns about the speciation both in solution and at the surface. The speciation diagram for dissolved europium is presented in Figure 3B of the paper [1], but is not discussed at all in the paper. We content that the red line denoted as the $\mathrm{Eu}(\mathrm{OH})^{2+}$ species in that figure should be the sum of all hydrolysis species instead.

Figure 1 (see below) shows some calculations at two different salt levels, that support this view. Indeed, the first hydrolysis species $\left(\mathrm{Eu}(\mathrm{OH})^{2+}\right.$ or $\left.\mathrm{Eu}(\mathrm{OH})++\right)$ has a small contribution and disappears with increasing $\mathrm{pH}$. With respect to surface speciation, it is now generally accepted that the absence of ionic strength effect on ion adsorption is not sufficient to conclude on the actual adsorption mechanism in terms of simple inner- vs. outer-sphere surface complexation, and spectroscopic investigations are often required to provide an accurate mechanistic description $[13,14]$. 

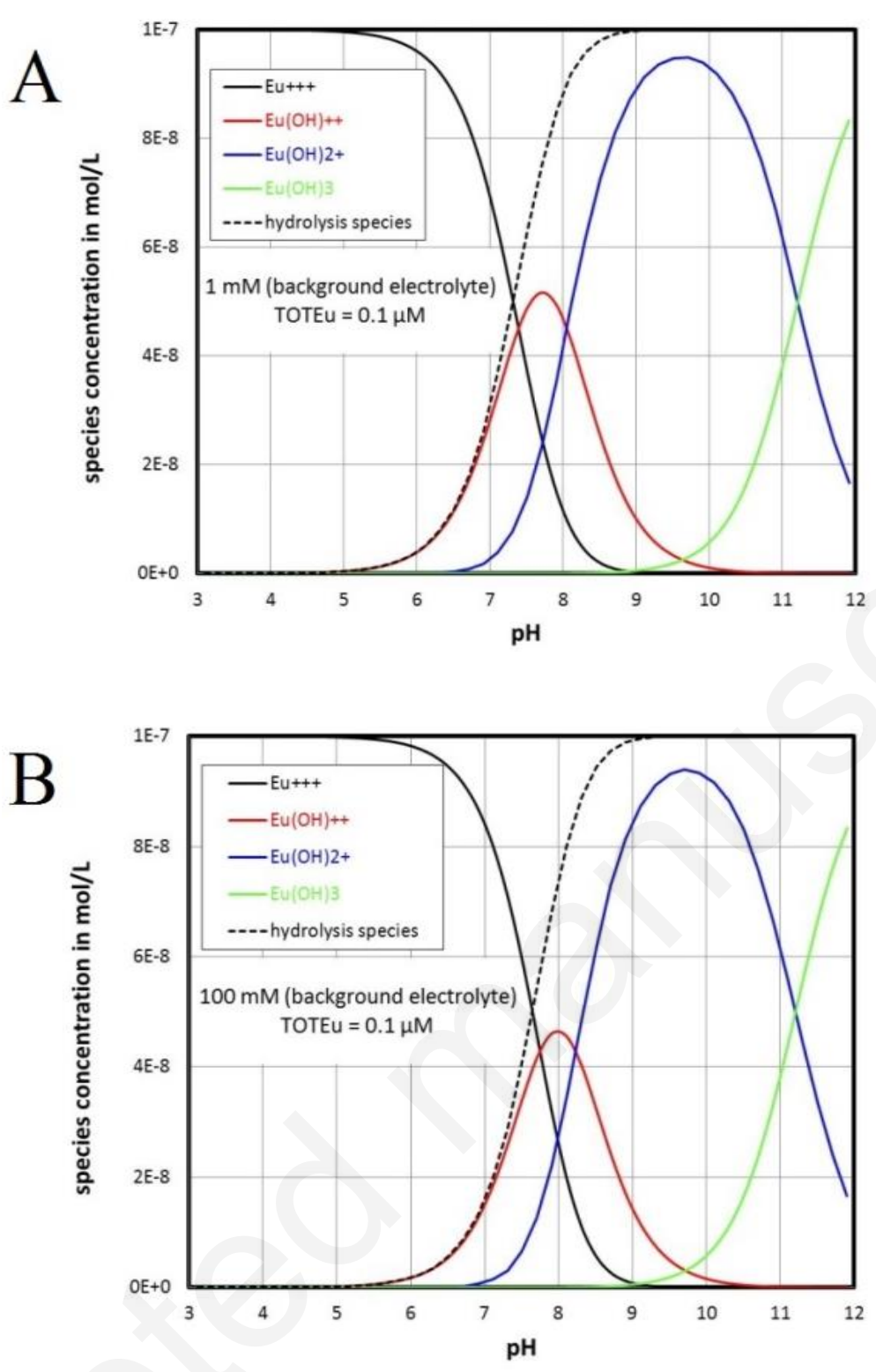

Figure 1. Aqueous speciation of $0.1 \mu \mathrm{M}$ Eu(III) in inert electrolyte solutions of $1 \mathrm{mM}(\mathrm{A})$ and $100 \mathrm{mM}$ (B). The full lines show contributions from the individual species while the dashed lines show the contribution from the sum of the hydrolysis species. These dashed lines probably correspond to what Zhu et al. [1] report as their red line in their Figure 2B and which they denote as the $\mathrm{Eu}(\mathrm{OH})^{2+}$ species, which we denote as the $\mathrm{Eu}(\mathrm{OH})++$ species (our red line).

In the spectroscopic part of their study, Zhu et al. [1] used XPS to characterize the surface of the solid phase and to obtain information on the Eu(III) adsorption mechanism. The O $1 s$ line in the survey spectra is of rather high intensity compared to the Fe and $\mathrm{S}$ lines, indicating that the surface is largely hydroxylated which would be consistent with intense water bands in the IR data. From the XPS O $1 s$ peaks, the authors conclude that the intensity and binding 
energies significantly change with $\mathrm{pH}$, but the differences actually appear rather limited on Figure 5C. Indeed from the data in Table 4 the $\mathrm{O} 1 s$ binding energies differ by no more than 0.2-0.3 eV. Furthermore, the S $2 p$ spectra may indicate a mixture of polysulfide/elemental $\mathrm{S}$ (binding energies around 163-164 eV) rather than S(-II) (binding energy around $161 \mathrm{eV}$ ) [4] which could indicate that surface redox reactions have occurred. Fe spectra at higher resolution may have shed light on the state of $\mathrm{Fe}$ in the pyrrhotite. Moreover, lines at 50 , $\sim 790,895-980 \mathrm{eV}$ were not identified on the survey spectra, and could be due to the presence of other elements (see above the IR data, where Si presence is discussed).

Related to the $\mathrm{Eu}$ (III) uptake mechanism the authors discuss the XPS spectra at pH 6 and 10, which would corroborate specific binding (i.e. what is usually called inner-sphere adsorption), but they do not discuss the spectrum at $\mathrm{pH} 4$ (Figure 5B). Do these results not support innersphere adsorption at $\mathrm{pH} 4$, where 40 to $50 \%$ of Eu were bound (Figure 3A)? Furthermore, adsorption does not depend on salt level at this $\mathrm{pH}$ but in the abstract it is reported that adsorption at the low $\mathrm{pH}$ was dominated by ion exchange. In this context we have wondered if the authors checked for uptake of $\mathrm{Eu}$ on the container walls or filters, which could also explain the relatively strong uptake at low $\mathrm{pH}$, particularly if low specific surface area material or low solid loading was studied.

\section{Conclusion}

We believe that this valuable work would benefit from more detailed information data and explanation to help in future evaluation and use of the work. We would be grateful if the authors could supply the information we are alluding to.

\section{References}

[1] Y. Zhu, H. Liu, B. Xu, P. Li, J. Mol. Liq. 218, 565-570 (2016)

[2] N. A. Chapman, J. A. T. Smellie, Chem. Geol. 55, 167-173 (1986).

[3] N. Belzile, Y.-W. Chen, M.-F. Cai, Y. Li, J. Geochem. Explor. 84, 65-76 (2004).

[4] J. R. Mycroft, H. W. Nesbitt, A. R. Pratt, Geochim. Cosmochim. Acta 59, 721-733 (1995).

[5] S. K. Bhargava, A. Garg, N. D. Subasinghe, Fuel 88, 988-993 (2009). 
[6] M. Tokonami, Nishiguchi K., N. Morimoto, Am. Mineral. 57, 1066-1080 (1972).

[7] E. R. Lipincott, A. Van Valkenburg, C. E. Weir, E. N. Bunting, J. Res. Nat. Bur. Stand. 61, 61-70 (1958).

[8] A. Naveau, F. Monteil-Rivera, J. Dumonceau, H. Catalette, E. Simoni, J. Colloid Interface Sci. 293, 27-35 (2006).

[9] S. Sjöberg, L. Lövgren, Aquat. Sci. 55, 324-335 (1993).

[10] J. Lützenkirchen, T. Preocanin, D. Kovocevic, V. Tomisic, L. Lövgren, N. Kallay, Croat. Chem. Acta 85, 391-417 (2012).

[11] J. Bebie, M. A. A. Schoonen, M. Fuhrmann, D. R. Strongin, Geochim. Cosmochim. Acta 62, 633-642 (1998).

[12] M. J. Dekkers, M. A. A. Schoonen, Geochim. Cosmochim. Acta 58, 4147-4153 (1994).

[13] J. Lutzenkirchen, J. Colloid Interface Sci. 202, 212 (1998).

[14] J. Lutzenkirchen, J. Colloid Interface Sci. 195, 149-155 (1997). 